\title{
Future directions for the ERS: Presidential plans
}

\author{
Francesco Blasi', Peter J. Barnes², Mina Gaga ${ }^{3}$ and Giovanni Battista Migliori ${ }^{4}$ \\ Affiliations: 'Dipartimento Fisiopatologia Medico-Chirurgica e dei Trapianti, University of Milan, IRCCS \\ Fondazione Cà Granda, Milan, and "World Health Organization Collaborating Centre for Tuberculosis and Lung \\ Diseases, Fondazione S. Maugeri, Care and Research Institute, Tradate, Italy. ${ }^{2}$ National Heart \& Lung Institute, \\ Imperial College, London, UK. ${ }^{3} 7$ th Respiratory Medicine Dept, Athens Chest Hospital, Athens, Greece.
}

Correspondence: Giovanni Battista Migliori: World Health Organization Collaborating Centre for Tuberculosis and Lung Diseases, Fondazione S. Maugeri, Care and Research Institute, Via Roncaccio 16, 21049, Tradate, Italy: E-mail: giovannibattista.miglioriafsm.it

@ERSpublications

The ERS, through the Presidential plan, contributes to better prevention and management of respiratory diseases in Europe http://ow.ly/n2JWA

The mission of the European Respiratory Society (ERS) is to promote respiratory health and alleviate suffering from respiratory disease and it fulfils this goal by promoting science/research, education and advocacy. Among the Society's activities are a successful annual Congress (attended by approximately 20,000 delegates), research fellowships, grants and seminars and a comprehensive educational programme through the ERS School [1-5]. The educational programme encompasses postgraduate courses during the Congress, courses and seminars on various topics throughout the year across Europe, a website with a wealth of educational modules and interactive materials. Importantly, the ERS School has initiated a training programme called Harmonisation in Education in Respiratory Medicine for European Specialists (HERMES), which sets training standards across Europe, runs examination and certification processes for the European Diplomas in Respiratory Medicine and Paediatric Respiratory Medicine, and allows mobility of European specialists. Furthermore, the ERS has a strong advocacy role through its Advocacy Committee and Brussels office, and through the European Lung Foundation (ELF) - the public voice of the ERS, which links with patients and patient organisations, provides information and listens to and empowers the patients' voices.

In a dynamic European and global setting, where health priorities in general (and respiratory medicine in particular) are changing rapidly, the ERS is planning to do even more in order to attract the attention of the media and policymakers and to bring more research funding into respiratory medicine. The ERS is proud to be the first major respiratory medicine society to have agreed and launched a public health Presidential plan, which is now being implemented.

A series of ERS Summits has been organised since 2011, when the European Respiratory Roadmap, which set out directions for respiratory medicine and research over the next decade, was approved in Leuven (Belgium) and was then discussed with officials from European Union in Brussels [6]. In 2012, the Tallinn (Estonia) Summit tackled the burning issue of respiratory inequalities and highlighted the striking differences in respiratory outcomes across Europe and even within countries and the way in which this related to poverty and availability of resources. This was followed in 2013 by the Summit on "Changing the natural history of respiratory diseases" organised in Dublin (Ireland). The objective of this Summit was to identify priority research topics that should be addressed at European level through interaction between all stakeholders - medical professionals, patients, the pharmaceutical industry, research funders and research

Received: July 052013 | Accepted: July 052013

Conflict of interest: The authors are current and former officers of the European Respiratory Society, as follows. F. Blasi: Past President; P.J. Barnes: President; M. Gaga: Past Secretary General; G.B. Migliori: Secretary General

Copyright @ERS 2013 
policymakers. The 2014 Summit has been planned in Rome (Italy), to discuss how we may more effectively translate basic research into clinical benefits in order to meet the needs of our patients.

The Presidential plan 2012-2013 was particularly innovative and aimed at implementing an important new initiative, the ERS/WHO Tuberculosis Consilium [7] as well as conducting two other infection-targeted activities, the European Forum for Tuberculosis Innovation and the cystic fibrosis project. These areas were chosen because both tuberculosis (TB) and cystic fibrosis are high priority in the infectious disease arena [8-10].

TB has attracted increasing public health and media attention due to the alarming rates of multidrugresistant tuberculosis (MDR-TB, defined as active TB cases infected by Mycobacterium tuberculosis strains that are resistant to isoniazid and rifampicin) and extensively drug-resistant tuberculosis (XDR-TB, superresistant $\mathrm{TB}$ cases caused by infection with strains that are resistant to at least one fluoroquinolone and one injectable second-line anti-TB drug in addition to resistance to isoniazid and rifampicin) [11-13]. MDRand XDR-TB are considered a serious threat to TB control and elimination in Europe [14] as their clinical outcomes are largely unsatisfactory and treating them is increasingly costly $[15,16]$. While in the MDR-TB cohort, treatment success is only 54\% (with 23\% default; $8 \%$ failure/relapse and $15 \%$ death), in $M$. tuberculosis strains with resistance patterns beyond XDR outcomes are even worse, with success ranging, from $40 \%$ down to $19 \%$, failure/relapse from $15 \%$ to $54 \%$ and death from $15 \%$ to $35 \%$ [15, 16]. In addition, the M/XDR-TB treatment regimens are much more toxic, long and expensive than those used to treat drugsusceptible TB cases $[17,18]$. Due to the frequent occurrence of adverse events, the limited availability of second-line anti-TB drugs, the real risk of acquiring further resistance and problems in patients' adherence to treatment, clinicians often face major challenges in successfully managing their patients. This is why, following a request by the World Health Organization (WHO) Regional Office for Europe, a consultation body (ERS/WHO Consilium) was jointly launched on September 6, 2012 during the 30th ERS Congress in Vienna, and a project has now been successfully implemented. Aimed at supporting clinicians in the daily management of difficult-to-treat cases, [7] this electronic platform, accessible via the ERS website (www. tbconsilium.org), has been already used by many clinicians in several countries of the world (fig. 1). Clinicians' specific queries are answered free-of-cost by global TB experts within a few days of cases being uploaded to the platform. The system also enables monitoring and evaluation of adherence to existing guidelines [19-21] as well as cross-border follow-up of TB cases throughout Europe.

The ERS has increased its commitment towards TB control and elimination in Europe through a second initiative, the European Forum for TB Innovation. This experts' think-tank is focused on innovative interventions that can be implemented based on evidence that is currently available. While an article from the elimination perspective has been already published [22], two other concept-manuscripts dealing with home care and community care of MDR-TB cases are now being finalised. As part of the Forum's activities, a special advocacy-oriented brainstorming workshop was organised within the 2013 ERS Conference in Barcelona. Forum experts (including representatives from WHO, the European Centre for Disease Prevention and Control and other agencies engaged in TB control and elimination activities) and advocacy stakeholders have been invited to discuss the core gaps existing in Europe to achieve elimination, based on the results of a recent ERS/WHO survey (table 1).

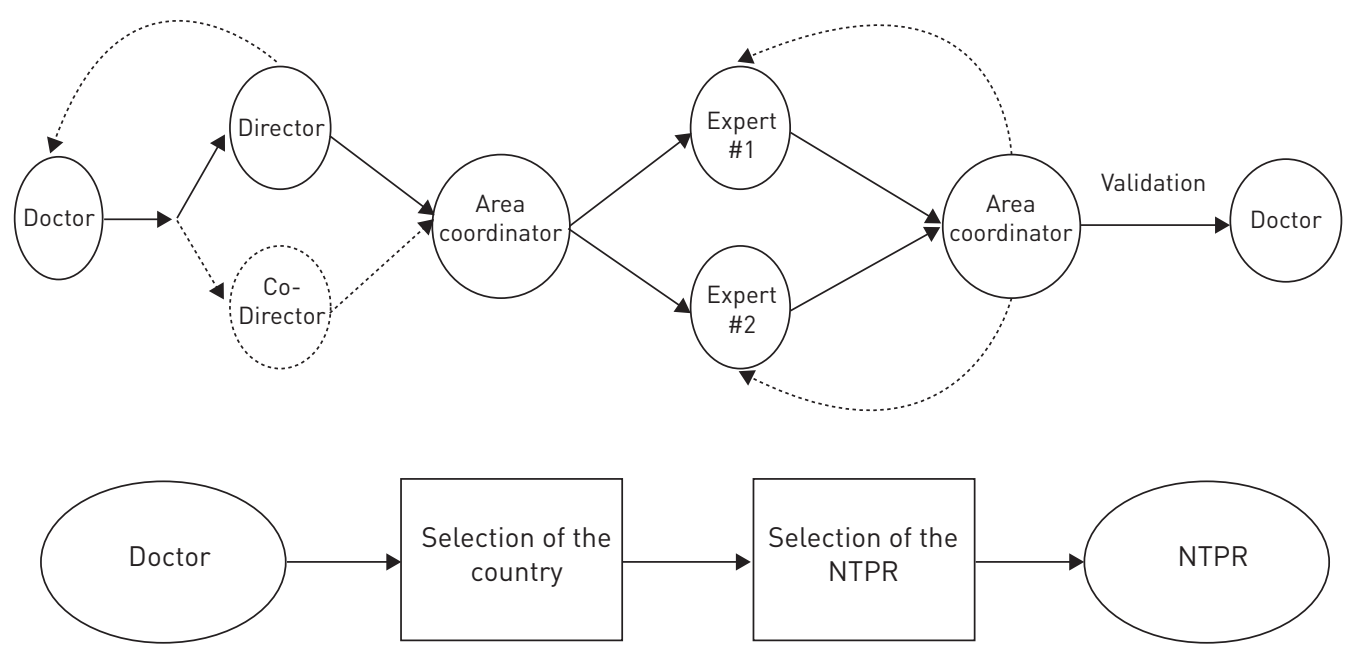

FIGURE 1 Schematic of the European Respiratory Society/World Health Organization Tuberculosis Consilium workflow. NTPR: national tuberculosis programme representative. 
TABLE 1 Core activities needing European funding to achieve tuberculosis (TB) elimination

1 TB control commitment, TB awareness and capacity of health systems

2

Surveillance

3

Laboratory services

$4 \quad$ Prompt and quality TB care for all

M/XDR-TB and TB/HIV co-infection

New tools for TB control and elimination

\section{Partnership and collaboration with countries}

Regulatory activities to ensure feasibility of all the activities below

European $\mathrm{MoH}$ platform to implement the activities below

Human resources development plan and training activities on TB elimination

Design and implementation of budgeted European and national elimination plans

European and national target establishment

Molecular epidemiology included in standard surveillance activities

European and national target establishment

Modelling capacity building and implementation at European and national level

European and national laboratory strengthening plan to ensure quality diagnosis and molecular epidemiological surveillance

Research aimed at identifying and addressing social and economic TB determinants le.g. housing, nutrition, smoking, etc.) with particular attention to high-risk groups and vulnerable populations

Regulatory activities ensuring universal free access to TB diagnosis and treatment and social protection

European and national plans to ensure early diagnosis, efficient treatment and throughcare of all types of TB and definitions of minimum standards of care in Europe

Prevention of emergence of further drug resistance through support to national and international clinical consultation bodies for difficult-to-treat TB cases le.g. ERS/WHO Consilium) and effective treatment of existing M/XDR-TB cases

Monitoring of adherence to guidelines and EU standards through existing resources (ERS/WHO Consilium) and periodic surveys

Capacity building on MDR-TB and TB/HIV clinical management

Definition of criteria and standards for reference centres

European and national plans to ensure effective testing and anti-retroviral treatment through quality implementation of TB/HIV collaborating activities

European and national plans to implement diagnosis and treatment of LTBI

European and national airborne infection control plans

Innovative research on new diagnostics, drugs and vaccines

Guidance on adoption of new tools to accelerate achievement of TB elimination with special attention to children, people infected with HIV and other immunosuppressed individuals (e.g. TNF- $\alpha$ )

European and national plans to ensure availability of all first- and second-line anti-TB drugs and prevention of stock-outs

European support to trials to develop new drugs and new safe, effective and shorter regimens

Rapid approval of new drugs and regulatory action to ensure their rational use to treat TB and LTBI

European and national programmes to ensure periodic programme reviews

Identification and scale-up of best practices

M/XDR-TB: multidrug/extensively drug-resistant TB; MoH: Ministry of Health; ERS: European Respiratory Society; WHO: World Health Organization; EU: European Union; LTBI: latent TB infection; TNF- $\alpha$ : tumour necrosis factor- $\alpha$.

The fight against cystic fibrosis (CF) in adults started through the establishment of an ERS-ECFS (European Cystic Fibrosis Society) Task Force aimed at reviewing the quality of current provision of CF care in Europe, estimating the burden of disease over the next 20 years, achieving consensus on adequate models of care and developing training curricula able to ensure capacity-building for adult CF in the future (table 2).

As part of the 2013-2014 Presidency, the Society launched a new edition of the European Lung White Book during the 2013 ERS Congress in Barcelona, providing an up-do-date review of the burden and costs of respiratory diseases across Europe. This provides the background researchers, clinicians, policymakers and politicians require in order to judge the need for more resources in respiratory medicine, and it serves to highlight the enormous burden of respiratory morbidity and mortality in Europe along with the astounding costs of respiratory diseases. It also provides data on the great inequalities in respiratory disease and care between European countries.

There have been remarkable advances in the basic science that underlies respiratory disease, but translating this new knowledge into clinical advances and benefits for patients has been difficult. The 2013-2014 Presidential plan will be aimed at strengthening basic research in respiratory medicine and facilitating its 
TABLE 2 Workplan of the joint European Respiratory Society-European Cystic Fibrosis Society Task Force, "Care Provision for Adults with Cystic Fibrosis in Europe"

Review of current provision of care in Europe (survey)

Estimate of numbers of people with cystic fibrosis in 5, 10, 15 and 20 years' time

Consensus on models of care

Curriculum development for training of adult pulmonologists in cystic fibrosis

Action plan for commissioning of care for adults

translation into benefits for patients. The ERS has a critical role to play in enhancing respiratory research across Europe, and the Society needs to integrate the advances in basic research more closely into clinical benefits, by increasing the basic research component of clinical symposia at the annual Congress and by bringing basic science into the Assembly structure. The Clinical and Basic Science Assemblies should become cross-cutting themes, with the disease-related Assemblies as the vertical components of the matrix (fig. 2). This change in structure will take time to evolve but should eventually lead to symposia that are more balanced between basic science and clinical medicine. We also aim to increase the number of nonmedical scientists at the Congress and to involve them more closely in the society. Within the 2013-2014 Presidential plan, we will evaluate the feasibility of strengthening our in-house research capacity, opening the way to the development of an ERS Research Agency that may facilitate the orchestration of respiratory research and networks across Europe. Achieving these goals is made possible through teamwork across the different ERS pillars, including the ERS office in Lausanne, Switzerland (the arm making finalisation of plans possible), the ERS office in Brussels (the advocacy arm acting at European Union level), the ERS publications office in Sheffield, UK [23, 24], the ERS Scientific Committee and the ELF.

Finally, the Junior Members' programme is of critical importance for the future as we need to train future generations of leaders in European respiratory medicine. The active participation of young colleagues in the Society's activities and in the shaping of its future is paramount and ensures a lively Society that caters to all members' needs. The new Junior Members' C Committee ensures a close contact between junior members, their Assemblies, the ERS School and Scientific Committee, as well as the ERS leadership and administration. The programme started in 2011 and junior representatives and members have their own website, meet regularly online and hold face-to-face meetings during the annual congress and the ERS Lung Science Conference (fig. 3). The chair and co-chair are elected by the junior members and represent them at the School and Scientific Committee meetings, while a junior member participates in each assembly's long range planning committee.

Overall, the innovative and ambitious Presidential plans integrate a result-oriented public health perspective and translational research outlook in respiratory medicine to the existing activities of the Society, which we hope will result in improved care for patients with lung disease and strengthen the standing of respiratory medicine within Europe.

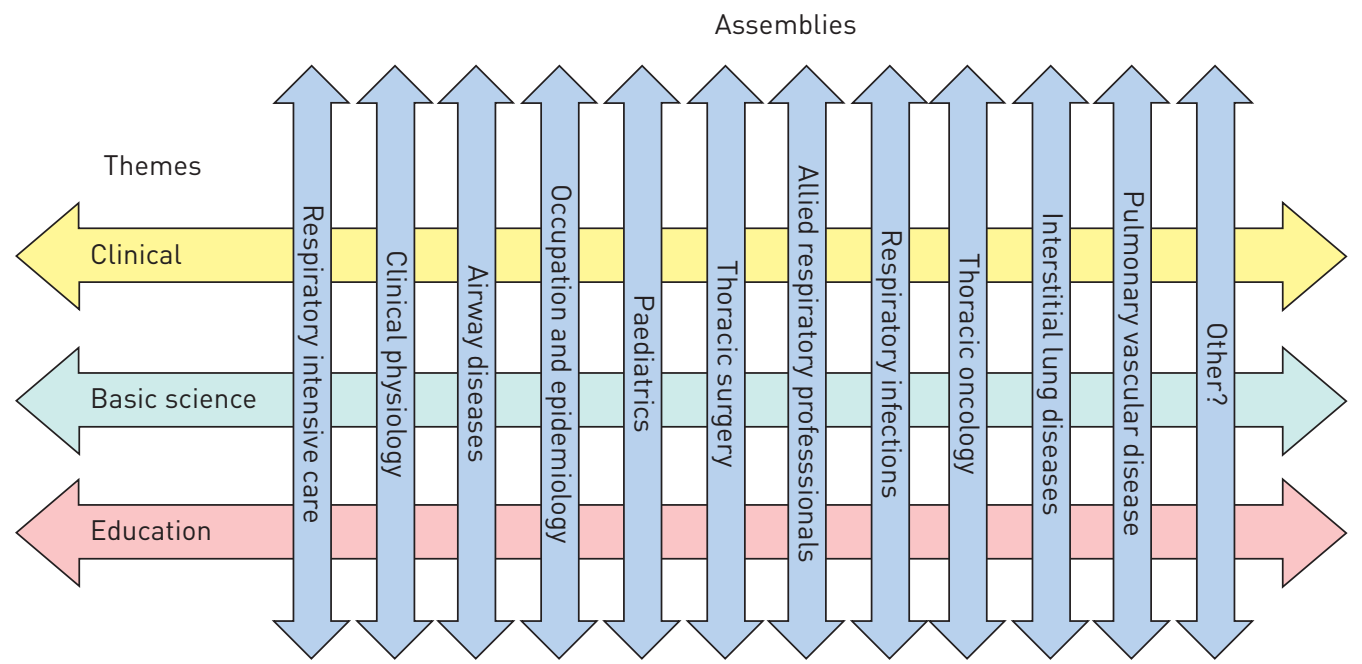

FIGURE 2 A potential operative matrix for the structure of the European Respiratory Society, showing how educational, clinical and basic research activities cut across the disease-specific Assemblies. 


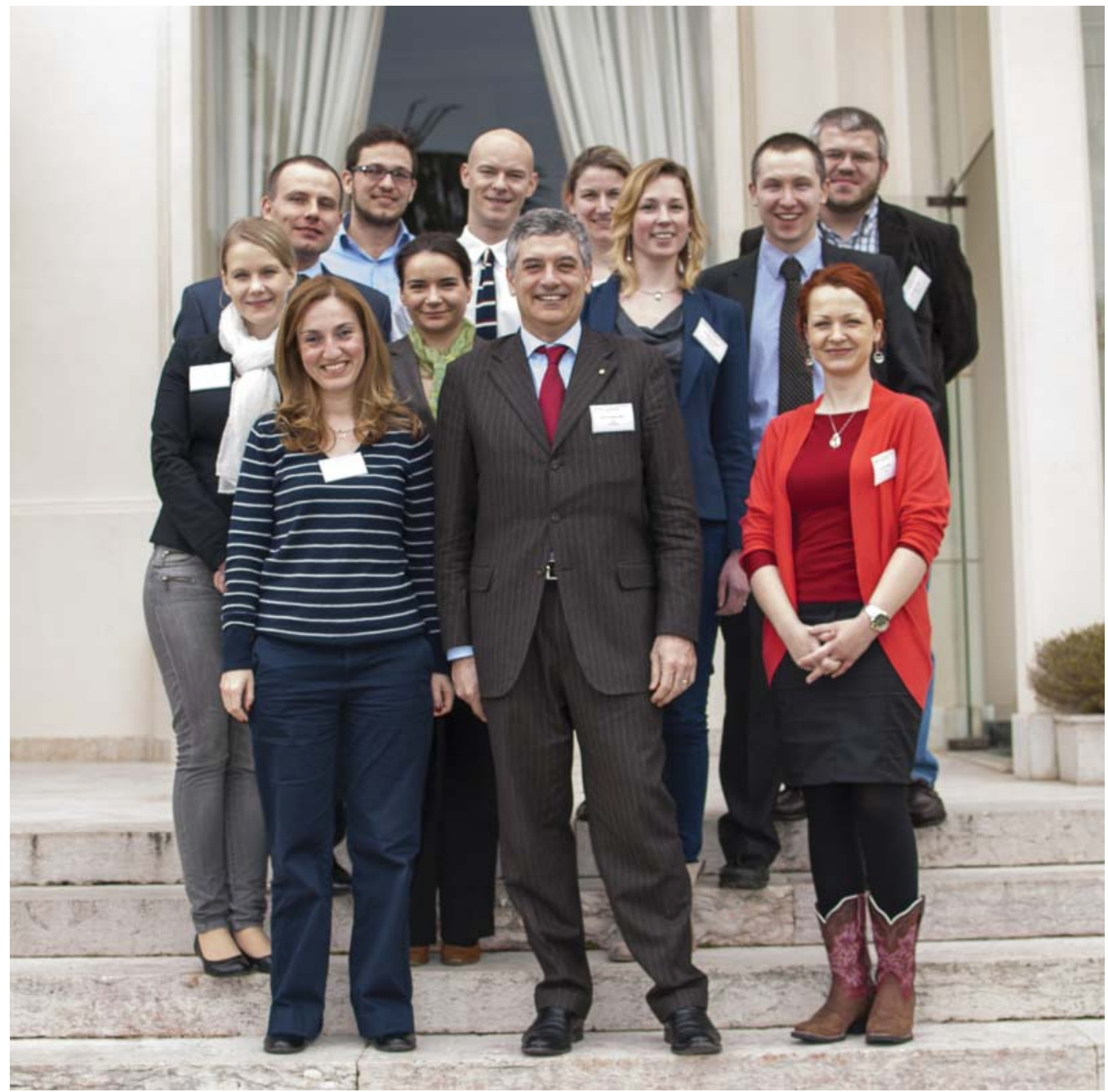

FIGURE 3 The Junior Members' meeting, Estoril, Portugal, 2013.

\section{References}

1 Palange P, Busari J, Hare A, et al. Perspectives in medical education: signposts to the future in educating respiratory specialists. Eur Respir J 2012; 39: 520-524.

2 Palange P, Noël J-LC, Simonds AK. The European Respiratory Society: future directions in medical education. Eur Respir J 2011; 38: 498-499.

3 Steenbruggen I, Mitchell S, Severin T, et al. Harmonising spirometry education with HERMES: training a new generation of qualified spirometry practitioners across Europe. Eur Respir J 2011; 37: 479-481.

4 Artigas A, Pelosi P, Dellweg D, et al. Respiratory critical care HERMES syllabus: defining competencies for respiratory doctors. Eur Respir J 2012; 39: 1294-1297.

5 De Backer W, Simonds AK, Horn V, et al. Sleep HERMES: a European training project for respiratory sleep medicine. Eur Respir J 2011; 38: 496-497.

6 Sibille Y, Decramer M, Nicod LP, et al. Directing the future of lung health: the European Respiratory Roadmap. Eur Respir J 2011; 38: 502-506.

7 Blasi F, Dara M, van der Werf MJ, et al. Supporting TB clinicians managing difficult cases: the ERS/WHO Consilium. Eur Respir J 2013; 41: 491-494.

8 Sly PD, Ware RS, de Klerk N, et al. Randomised controlled trials in cystic fibrosis: what, when and how? Eur Respir J 2011; 37: 991-993.

9 Woodhead M. New guidelines for the management of adult lower respiratory tract infections. Eur Respir J 2011; 38: $1250-1251$.

10 Woodhead M. Prescribing and guidelines: both must improve to combat antimicrobial resistance. Eur Respir J 2011; 38: 9-11.

11 Raviglione M, Marais B, Floyd K, et al. Scaling up interventions to achieve global tuberculosis control: progress and new developments. Lancet 2012; 379: 1902-1913.

12 Migliori GB, Dara M, de Colombani P, et al. Multidrug-resistant tuberculosis in Eastern Europe: still on the increase? Eur Respir J 2012; 39: 1290-1291. 
13 Skrahina A, Hurevich H, Zalutskaya A, et al. Alarming levels of drug-resistant tuberculosis in Belarus: results of a survey in Minsk. Eur Respir J 2012; 39: 1425-1431.

14 Migliori GB, Sotgiu G, D'Ambrosio L, et al. TB and MDR/XDR-TB in European Union and European Economic Area countries: managed or mismanaged? Eur Respir J 2012; 39: 619-625.

15 Falzon D, Gandhi N, Migliori GB, et al. Resistance to fluoroquinolones and second-line injectable drugs: impact on multidrug-resistant TB outcomes. Eur Respir J 2012; 42: 156-168.

16 Migliori GB, Sotgiu G, Gandhi NR, et al. Drug resistance beyond extensively drug-resistant tuberculosis: results from a large individual patient data meta-analysis. Eur Respir J 2013; 42: 169-179.

17 Loddenkemper R, Sotgiu G, Mitnick CD. Cost of tuberculosis in the era of multidrug resistance: will it become unaffordable? Eur Respir J 2012; 40: 9-11.

18 Diel R, Rutz S, Castell S, et al. Tuberculosis: cost of illness in Germany. Eur Respir J 2012; 40: 143-151.

19 Migliori GB, Sotgiu G, Blasi F, et al. Towards the development of EU/EEA Standards for Tuberculosis Care (ESTC). Eur Respir J 2011; 38: 493-495.

20 Migliori GB, Zellweger JP, Abubakar I, et al. European Union Standards for Tuberculosis Care. Eur Respir J 2012; 39: 807-819.

21 Falzon D, Jaramillo E, Schünemann HJ, et al. WHO guidelines for the programmatic management of drug-resistant tuberculosis: 2011 update. Eur Respir J 2011; 38: 516-528.

22 Blasi F, Reichman LB, Migliori GB. Presenting the European Forum for TB Innovation: innovative thinking in progressing towards TB elimination in Europe. Eur Respir J 2012; 40: 806-808.

23 Dinh-Xuan AT, Brusasco V. The eds' farewell and a confident look back to the future. Eur Respir J 2012; 40: 1309-1311.

24 Migliori GB, Soriano JB, Brusasco V, et al. ERJ peer reviewers: does this pillar of the Journal's quality need help? Eur Respir J 2011; 38: 251-252. 